\title{
Caring for Moderate to Severe Dementia Patients - Malaysian Family Caregivers Experience
}

\author{
Zuria Idura $\mathrm{AM}^{\mathrm{a}}$, Noorlaili $M \mathrm{~T}^{\mathrm{b}}$, Rosdinom $\mathrm{R}^{\mathrm{a}}$, Azlin $\mathrm{B}^{\mathrm{a}}$, Tuti Iryani $M \mathrm{D}^{\mathrm{a}}$ \\ ${ }^{a}$ Department of Psychiatry, Universiti Kebangsaan Malaysia Medical Centre (UKMMC), Cheras, \\ Kuala Lumpur, Malaysia \\ ${ }^{b}$ Department of Family Medicine, Universiti Kebangsaan Malaysia Medical Centre (UKMMC), \\ Cheras, Kuala Lumpur, Malaysia
}

\begin{abstract}
Introduction: Caring for those with dementia affects the quality of life for both the caregivers and the patients themselves, particularly in the informal care system here in Malaysia. To date, only a few studies have explored from the family caregivers' perspectives in the communities of different cultural background. The purpose of this study is to describe the Malaysian family caregivers' perspectives of their experiences in providing care to for their family members suffering from moderate to severe dementia in Kuala Lumpur, Malaysia. Methods: This qualitative study involved in-depth individual interviews with twelve caregivers to patients with moderate to severe dementia. Participants were recruited via purposive sampling from the outpatient psycho-geriatric clinic at UKM Medical Centre, Kuala Lumpur. All interviews were audio-recorded and transcribed verbatim. Transcribed data was later analysed using a thematic approach. Results: Four themes identified in this study were; i) the feeling that 'it is like caring for a baby', ii) the caregivers' perception of inadequate knowledge and skills, iii) the need for caregivers' support system and iv) the importance of spirituality in enhancing care giving experiences. Conclusions: The framework of care shared by the caregivers in this study demonstrated strong cultural and spirituality influences in addition to the common issues of the challenges in managing the behavioural and psychological symptoms in people with dementia. Hence, culture and spirituality aspects should be addressed in the development of appropriate intervention to manage the needs of informal caregivers in this community.
\end{abstract}

KEYWORD: caregivers, dementia, informal care, qualitative study, Malaysia.

\section{INTRODUCTION}

Dementia is a disorder characterized by the development of multiple cognitive deficits. The illness affects patient's capacity to remember, ability to think abstractly, language functions, orientation to time and place, appropriate judgement and consequently, personality changes. As a result, patients with dementia will lose the functional capacity for independence and personal care and eventually will require assistance in their daily activities. Family caregiver was defined as a family member responsible for taking care of a spouse or parent with dementia. ${ }^{1}$ Family caregivers of people with dementia, often called the "invisible second patients", are critical to the quality of life of the care recipients.

Corresponding author:

Dr. Noorlaili Mohd Tohit @ Mohd Tauhid

MD (UKM), MMed (FMed) ((UKM Malaysia),

PhD (Monash University Australia),

Department of Family Medicine,

Universiti Kebangsaan Malaysia Medical Centre

(UKMMC),

Jalan Yaacob Latif, Bandar Tun Razak, Cheras,

56000 Kuala Lumpur, Malaysia

Tel: +603-91459474 Fax: +603-91459479

Email : laili@ppukm.ukm.edu.my
Family care giving has often been associated with negative outcomes such as social isolation, depression, emotional and physical strain, poor physical health and decreased ability to work. ${ }^{2-4}$ While many of the researches focused on burden and other negative aspects of family care giving, positive aspects of care giving do exist, ${ }^{5,6}$ such as sense of self-efficacy, feeling of accomplishment, a sense of meaning, satisfaction, well-being and improve quality of relationships. ${ }^{7}$ These positive experiences may help sustain family members in their role as caregivers. ${ }^{6}$ On the other hand, individuals and families seek religious healing to improve their mental, physical, emotional, and spiritual health. Religious coping is a way to deal with mental distress. ${ }^{8}$ A study in Pakistan showed local people perceived and used religious venues as major sources of help when dealing with physical, social, and mental-health problems. ${ }^{8}$ Another qualitative study done in India, covering urban and rural areas for 75 family caregivers caring for family members with serious mental illness highlighted that religious and spiritual dimensions facilitated a sense of control, hope and better caregiver adjustment. ${ }^{9}$

Family caregivers do not only deal with the tasks of providing care, but also with the impact of care giving on their own lives and emotions. Aranda and 
Knight's socio-cultural stress and coping model suggests that cultural factors within ethnic/racial minority population may influence caregivers' beliefs, attitudes, experiences and outcomes of caring for their family members. ${ }^{10,11}$

Malaysia, a multiracial country with a population of 28.3 million, profess a variety of faiths in which 61.3\% are Muslims, 19.8\% Buddhists, 9.2\% Christians and $6.3 \%$ Hindus. $^{12}$ The estimated prevalence of moderate to severe dementia in a population aged 65 years or older is consistently reported at approximately $5 \%{ }^{12}$ A local study done 2003 by Choo W.Y., et al on 70 Malaysian caregivers of dementia patients found higher level of burden among Chinese caregivers compared to the other 2 major ethnics Malay and Indian. ${ }^{13}$ Rosdinom et al. in 2011 also found that the Malay sample/respondents perceived the burden of care as less stressful compared to other racial groups Some studies have reported higher level of burden among female and daughter carers compared to male and sons ${ }^{15-21}$, however a local study done by Rosdinom et.al. , showed no significant relationship between caregiver burden and their gender. In addition, closer kinship between caregiver and patients deemed no significant burden. ${ }^{14}$

The construction of caregiver experiences may demonstrate universality in its multidimensional interpretations, but there are gaps in our understanding on how it is being viewed in different cultures. Hence, this study aims to explore and identify Malaysia's multi-ethnic caregivers' perspectives on their experiences in providing care for family members with moderate to severe dementia.

\section{MATERIALS \& METHODS}

\section{Study design}

This study adopted a basic interpretative qualitative study $^{22}$ which took constructionist stance using purposeful sampling method. The data was analysed thematically. Such qualitative study will help us gain better insight of the caregivers' experiences and their perspectives in caring for family members with dementia.

\section{Recruitment and sampling}

This study received ethical approval from the University Kebangsaan Malaysia Ethical Committee (JEP-2016-033). Participants were recruited among family caregivers of patients with all types of dementia attending the psycho-geriatric and memory clinics in UKM Medical Centre, Kuala Lumpur. The list of patients with moderate to severe dementia (based from the latest mini mental state examination (MMSE) recorded in patient's file) and their caregivers were identified either through the clinic appointment books or during their visit to the clinics. The caregivers were briefed regarding the study purpose before seeking their written consent. Once they agreed to participate, the researcher would arrange for the interview date and venue according to caregivers' preferences (either in the clinic or in their homes).

In this purposive sampling, maximum variation strategy was used by recruiting the participants according to gender, ethnicity and relationship with care recipient. ${ }^{23}$ Participants must be aged 18 or above, able to converse in English and/or Malay languages and currently living together and providing care for a family member with moderate to severe dementia for at least one year. Paid caregivers, caregivers with concurrent life threatening medical conditions or underlying acute psychiatric illness were excluded. The recruitment of participants was conducted until data saturation was achieved i.e. when no new theme could be further derived. ${ }^{24}$

\section{Data collection and analysis}

Participants chosen for this study were heterogeneous which comprised both female and male caregivers; with different/wide range of ages and different cultural and religious backgrounds. Twelve semi-structured individual interviews using a topic guide were conducted from February 2016 to June 2016. Each interview was conducted between 40-60 minutes and audio-recorded. The topic guide consisted of open-ended questions with in-depth probing to allow a thorough understanding about the objectives in their own words to gain rich qualitative data.

The framework of research questions comprised of four broad questions: (1) What are the caregivers' experiences in caring for the person with dementia? (2) How does the care giving responsibilities affect their life? (3) How do they cope with their care giving responsibilities? (4) What are their needs and expectations? Information about their sociodemographic characteristics was collected using a structured questionnaire, to provide better understanding of the caregivers' characteristics.

All interviews were transcribed verbatim. Although transcription was a tedious process, no editing was done to maintain its originality. Transcripts were read and analysed by the research team, comprised of the primary investigator and 4 co-supervisors which included a psycho-geriatrician.

The data was later analysed using a thematic analysis approach. ${ }^{25}$ As this qualitative research project explored unknown perspectives, the thematic analysis process was inductive in nature, data-driven and provided a rich thematic description of the entire dataset'. ${ }^{25}$ It involves data familiarisation, manually generated initial free codes, reviewing the free codes and re categorising them where ever necessary. Further steps included identifying connections between the free nodes; 
before forming into key themes. Themes identified were later reviewed for possible overlap and their degree of importance as a theme or as a subtheme assessed. Finally, after repeated reviews and rearrangement of themes and subthemes, each theme was then defined by assigning them with a label..$^{25}$

For the purpose of presenting the data in its written form, some parts of the interview that was conducted in Malay were later translated into English. Care was taken to ensure accuracy of meaning and its content. Most of the English translations of the interviewees' statements had been quoted to retain the essence of their actual words wherever verbatim translation was not possible. In order to protect the anonymity of participants, pseudonyms had been assigned to participants and used in the presentation of the findings.

\section{RESULTS}

\section{Participants}

Twelve family caregivers of Malay, Chinese and Indian ethnicity participated in the study. Table 1 presents the socio-demographic characteristics of all study participants. The participants' age ranged from 30 to 83 years old, and half of them $(n=6)$ aged 60 years and above. Majority of the participants were female $(n=10)$ and two-thirds of them $(n=8)$ cared for their own parents, including one male caregiver. A quarter of the participants $(n=3)$ were caring for their own spouses. The majority of participants were still employed $(n=7)$.

Table 1. Characteristics of caregivers (CG) and patients with dementia in the study $(n=12)$

\begin{tabular}{|c|c|c|c|c|c|c|c|c|}
\hline $\begin{array}{l}\text { CG's } \\
\text { pseudo- } \\
\text { name }\end{array}$ & $\begin{array}{l}\text { CG's Age } \\
\text { (years) }\end{array}$ & $\begin{array}{l}\text { CG's } \\
\text { Gender }\end{array}$ & $\begin{array}{l}\text { CG's } \\
\text { Race }\end{array}$ & $\begin{array}{l}\text { CG's Rela- } \\
\text { tion to } \\
\text { patients }\end{array}$ & $\begin{array}{l}\text { CG's } \\
\text { Employment } \\
\text { status }\end{array}$ & $\begin{array}{l}\text { Patients' } \\
\text { age (years) }\end{array}$ & $\begin{array}{l}\text { Diagnosis of } \\
\text { patients }\end{array}$ & $\begin{array}{l}\text { Dementia } \\
\text { severity }\end{array}$ \\
\hline $\mathrm{P} 1$ & 64 & Female & Chinese & Daughter & Retired & 84 & VD & Moderate \\
\hline P2 & 83 & Male & Malay & Husband & Retired & 78 & $A D$ & Severe \\
\hline P3 & 35 & Female & Chinese & Daughter & Employed & 70 & LBD & Severe \\
\hline P4 & 30 & Female & Malay & $\begin{array}{l}\text { Daughter- } \\
\text { in-law }\end{array}$ & Employed & 68 & VD & Moderate \\
\hline P5 & 58 & Female & Malay & Daughter & Retired & 82 & $A D$ & Severe \\
\hline P6 & 81 & Female & Chinese & Wife & Unemployed & 81 & VD & Moderate \\
\hline P7 & 38 & Female & Malay & Daughter & Employed & 76 & $A D$ & Moderate \\
\hline P8 & 46 & Female & Malay & Daughter & Employed & 71 & LBD & Severe \\
\hline P9 & 60 & Female & Chinese & Daughter & Employed & 91 & $A D$ & Moderate \\
\hline P10 & 46 & Female & Chinese & Daughter & Employed & 79 & VD & Moderate \\
\hline P11 & 58 & Male & Chinese & Son & Employed & 83 & $A D$ & Severe \\
\hline P12 & 80 & Female & Indian & Wife & Unemployed & 80 & $A D$ & Severe \\
\hline
\end{tabular}

CG: Caregiver VD: Vascular Dementia AD: Alzheimer's disease LBD: Lewy Body Dementia

In this study, four general themes of caregivers' experiences were identified as listed/shown below:

\section{Theme 1:}

\section{It is like caring for a regressing baby}

The emotional impact experienced by family caregivers, similar to taking care of a 'baby' was an important theme described by the participants. When a baby is born, they normally progress and achieve their developmental milestone accordingly which often results in joy. However, a patient with dementia is seen as a 'regressing baby', which is defined as the regression of the behaviour to the extent that the caregiver could not anticipate the outcome; where. regressing instead of progression seems normal.

\section{a) Reversal of parenting role}

Many of the participants articulated the experience of looking after their elderly parents akin to the feeling of caring for a little baby or a child, which 
required higher levels of care and attention towards the patients. This was proven to be labour intensive and time consuming for some caregivers.

A 35 year-old working mother expressed her feelings as:

"Very challenging. I have to take care of her (patient) and my children are 7, 5 and 2 years old, and one [more] is coming (pregnant). The feeling is just like I have 4 children since she is just like a child now." (P3)

While a 60 year-old daughter also expressed a similar situation in taking care of her 91 year-old father:

"So now he's like, really regress till to like becoming like a child, always tell you, don't do this, he will want to do it." (P9)

An 80 year-old wife also complained that:

"He (husband) is like a newborn. He is a baby now." (P12)

\section{b) Caregivers' life adjustment}

There is something unique about the caregivers' life adjustment in taking care of demented patients compare to other scenario of other illness or even social restructuring. A mother working from home decided to send her small children to a day care, in order for her to take care of her mother.

"I send my 2 kids to the nursery. Morning definitely I have to spend time at work. I am a graphic designer. Because I told them that I have to take care of my mother, the company allowed me to work from home. Really appreciate it." (P3)

It could also be the culture that the children feel it is their responsibility to take care of the family member with dementia. Lack of availability of systematic day care centre/nursing home is always an issue here in Malaysia.

"In nursing home, they should have dementia programme or support group. The nursing home is not a place where they just sit and wait to die." (P1)

Same participant also added:

"We went for travelling. After 2 weeks we came back, something wrong with the leg again because she sleeps a lot in my absence. No exercise. Even if I left her with my sister-in-law, sure got problem." (P1)

An 81 year-old wife who lives alone with her husband shared her experience of adjusting her time for grocery shopping;
"Usually I took him for breakfast, chit chat a bit and then went home. He takes his medicines and fall asleep. So I have one hour to do my shopping at a supermarket." (P6)

Interestingly, some caregivers addressed the issue of their own diet adjustments to suit patient's needs. One of them mentioned:

"Only thing is now the food. He can't swallow. Every time we have to order, 'taufu', egg, all soft-soft thing. We order the thing he eats, so everyone can eat [sigh]." (P9)

Hence, further exploration to see the uniqueness of life/lifestyle adjustment for caregivers to demented patient would be a worthwhile capturing.

\section{Theme 2:}

Caregivers' perception of inadequate knowledge and skills

Realising inadequacy of knowledge comes from acknowledging the difference between expectation and reality. The expectation of aging and disease is rather different. They see changes in behaviour based on their expectation of aging. When patient's behaviour is out of norm, caregivers misconstrued it as 'misbehaved'.

\section{a) Unable to recognise early signs of dementia}

Caregivers encountered confusion regarding the illness/symptoms which results in the delay in understanding the diagnosis. Three daughters of a caregiver recalled their poignant feelings;

"You know, because we didn't understand that it was part of her disease. Ah/Argh, very irritated! of course, we didn't have as much patience at that time. Huh! We didn't know." (P1)

A 35 year-old working mother took many years struggling to understand her mother's illness.

" 3 to 4 years ago, me and my sister discovered something wrong with her (mother) when she started to tell funny story and started to forget many things. It took us 3 years before we brought her to hospital." (P3)

A 46 year-old daughter shared her guilty feelings;

“Initial part, I'm having difficulty to accept my father's illness because I don't understand how the illness like. I've done lots of sin for being rude and harsh towards him because I don't understand what Lewy Body Dementia is." (P8)

Discrepancies in knowledge not only revolved within the among low-educational background of/poorly 
educated participants/caregivers but also among the professional/highly educated group.

\section{b) Struggling to handle patients}

Most of patients exhibited various behavioural and psychological problems ranging from insomnia, agitation/irritability to psychosis. The caregivers were actively coping in carrying out their role, yet they were actually struggling in silence since they were not trained.

A 60 year-old retired government officer struggling in her journey in taking care of her mother with dementia;

“We weren't trained. Anger, resentment and irritation.... and no patience. Because the government is not actually proactive to help all these people. "(P1)

While an 80 year-old wife was also struggling to take care of her husband of similar age;

"At night I cannot sleep. I wake up few times checking on him. I'm afraid if he might fall down. Old people if they fall, then that is it. They will become bedridden." (P12)

She also added difficulties in carrying out some duties especially in handling daily care;

"I take him to the barber shop. To take him down from the car is so difficult. After shaving, to bring him back to the car also difficult. Everybody is looking. I feel shy also, but (pause) have to do." (P12)

\section{Theme 3:}

The need for caregivers' support system

The need for caregivers' support arises because of unmet expectations. The caregivers discussed about the need for a better support system and shared their ideas on how they organised effective coping mechanisms to suit the framework of existing support system

\section{a) Formal and informal support}

The caregivers shared difficulties and challenges faced due to the lack of support system hence resulted in increasing personal burden. Most of them were looking for facilities or support services such as day care or respite centre. Regardless of the severity of dementia, almost all caregivers opted for support group as part of resource system as they believe that strong support systems may ease their burden.

A retired government servant described the significant role of Alzheimer's Disease Foundation of Malaysia (ADFM) in helping her managed her late
"We go for regular talks by the Alzheimer Centre. And then we got more realization about her-what to expect. I think we are better equipped now lah." (P1)

A 46 year-old daughter pointed out her concern regarding suitability/availability of day care centre for patients with dementia;

"At one point, I need to send him (father) to a day care centre since I need to work and no one can take care of him after my mother passed away. However, there were limited places in the day care that suits him and all of them are expensive. I ended up taking loan from a bank." (P8)

Having a maid as an assistant also provided a great help in assisting the family caregiver.

He doesn't listen to my sister. He is more scared of the maid because the maid always says that if he doesn't listen, she will go back and he will be put into a home. (P9)

\section{b) The need to ventilate their feelings}

There were often mixed feelings along their journey as family caregivers fluctuating between positive and negative emotions. There were times when they need to ventilate their feelings not only to friends or professionals but also to God.

A 35 year-old, working mother from home, who is also currently expecting a newborn, shared her experience in using religion as part of buffering in coping with stress of taking care of her mother, who was newly diagnosed as suffering from dementia.

"I'm a Christian. Especially when it is stressful and emotional at that time, we pray to God. I feel at ease." (P3)

One on the caregivers, a 58 year-old business woman requested referral to a psychiatrist to get help for her to cope with her care giving role and as an avenue for her to express her emotions;

“Mentally I'm not strong. My mother's Alzheimer's make my life hay-wire. I'm looking forward every follow-up with my psychiatrist to vent my feelings. I need help. I want help." (P5)

An elderly wife also expressed her feelings;

"I feel relieved to share things with you. I can't share with others even to my best friend. Husband is part of you also, until one of you die. If good thing you can tell, but not bad things." (P12)

\section{c) The need for private time or respite}

Most of the caregivers had taken the initiative to have some time alone for respite from their challenging 
role as a caregiver.

Living in the current "sandwiched generation" whereby (caring for elderly/demented parents and her own children), a female caregiver gets help from her sister for respite on alternate weekend. She sighed;

"We actually need to take turn. And she (sister) also needs to sometimes take my mom out. She will come on alternate weekend to take my mom back to her house." (P3)

Another caregiver used work-related excuses to get her 'golden' time with her 2 year-old daughter and husband.

"I don't have life. I don't have privacy. Sometimes I need to lie to her (mother-in-law) that I'll be leaving for outstation, so that I would have time for me and my family." (P4)

Another caregiver decided to fix a 'me' / private time for respite through religious coping by attending religious classes frequently.

"I will make time for myself every Tuesday, Wednesday and Thursday. Only 2 hours for religious classes, hence to release tension." (P5)

Theme 4:

The role of spirituality enhances care giving experiences

\section{a) Care giving role acceptancelfilial piety}

Filial piety is characterized by respect, honour, fidelity, devotion, dutifulness, and sacrifice on the part of children for their parents. Most of the caregivers in this study especially Chinese, described it as a sense of obligation or reciprocity, which is reinforced by the practise of their ancestor worship. The caregivers unquestionably obeyed the needs or wishes of their elderly parents. Traditional views on caregiving may also be influenced by moral or religious aspects that stem from Taoism, Confucianism and Buddhism. ${ }^{26}$

\section{A 64 year-old daughter described:}

"When I first took on my mother I had a..... huh.... image of her as a mother. Because think about it, I don't think she's going to be around forever. It's like filial piety." (P1)

Nevertheless, in the context of Islam, it also emphasizes religious values and obligation towards the elderly. A 46 year-old single/unwed daughter, sacrificing her life taking care of her demented father illustrates;

"If our father can care for us when we were young, Allah has given me the grace to repay my parents for their effort in raising us “(P8).

A 58 year-old businessman, viewed caregiver's burden in a positive way, viz as a lifetime experience in taking care of his 83 year-old mother.

"This is the only lifetime experience. You don't have another chance if they're gone. This is the moment to cherish. If you have that attitude, you should be able to cope with it in a more positive manner." (P11)

\section{b) Feeling rewarded/blessed in different ways}

The moment a family member is diagnosed with dementia, many caregivers viewed their future as challenging especially for those who are working or still studying.

Caring for a demented mother-in-law is definitely challenging but is seen as being appreciated in a different way as shared by this 30 year-old who is working while studying part-time;

"I am grateful to be able to care for her (mother -in-law) and treat this as end-of-life blessing for me. We need to be mindful of Allah's plan. Although I was busy caring for my mother-in-law, I still managed to obtain an $A$, maybe because she was silently praying for me in her heart. Taking care of her is my hereafter reward." (P4).

Another caregiver also shared the same experience; where she realised that each caregiver has his/her own experience. Each of them viewed their caregiver's experience through a positive perspective;

"I opened my first kindergarten in 2008, in 2009 I opened my second branch and the third in 2012. I felt that my success was a blessing as a result of caring for my parents. Allah makes things easier for us when we care for our parents. This has made me more enthusiastic" (P7).

Talking from experience, a 46 year-old single daughter viewed her caregiver journey as;

"Allah has tested me but I believe He has provided me an advantage by paving the way for me to get a scholarship to pursue my Masters and PhD. All these were possible because I cared for my father." (P8).

\section{DISCUSSION}

Caregivers' contribution in caring for their dependents remains immense and unfortunately, largely unrecognised. Caregivers experienced significant burden of care in patients with high BPSD (Behavioral and psychotic symptoms of dementia) scores. ${ }^{27}$ Family caregivers of demented patients not only have to deal with the errands of 
providing care, but also with the impact which caregiving has on their psychological wellbeing. Thus, caring for patient with dementia is more challenging than caring for a patient without dementia. The experiences faced by caregivers in this study can be generalised to reflect / inferred other caregivers in throughout the country as sufficient abstractions and analysis were put in place.

Studies have shown that most caregivers struggled with the constant need to keep an eye on their family members with dementia, particularly due to lack of knowledge regarding the illness. A qualitative study done in Hong Kong among caregivers of persons with dementia using focus group discussion reported five key themes ie i) 'confusion regarding diagnosis', ii) 'emotional impact', iii) 'difficulty in coping with the care recipient behaviours', iv) 'provision of care recipient's daily care needs is demanding' and v) 'conflicts among social roles'. ${ }^{28}$ The nature of care is challenging since caregivers not only have to deal with the physical task, but also with the emotions when dealing with behavioural and psychological aspects in demented patients. ${ }^{29}$

Dementia as a diagnosis remains under-diagnosed in this community / our local community not only among the family members but also among a few clinicians. Most people still associate dementia as part of a normal aging process. This is supported by a study which showed older Asians are more likely to consider dementia as part of ageing process and regarded that care for the elderly ought to be provided by families or friends. ${ }^{30}$ Interpreting the symptoms as part of normal ageing partly attributed to the late diagnosis. Almost all of our caregivers / the caregivers in this study encountered the same issue. Lack of knowledge about the illness may lead to stigma and caused negative feelings from caregivers ${ }^{31}$; which prevent them from discussing about family members with dementia. In a study among Egyptian families; it was reported that they tend to keep caring for their mentally ill relatives even though they experience feelings of powerlessness, lack of support, isolation, embarrassment and stigma. ${ }^{32}$ While in our study, not all caregivers seemed to be avoiding discussion regarding the illness. Few caregivers seemed keen for support by joining the ADFM to equip themselves with knowledge or seek professional help to ventilate their feelings.

In addition, caregivers did have positive experiences as it helped improve the relationships among family members. Increasing severity in care recipients' illness also resulted in less carer's burden due to increased family support and fewer complaints from others about the carers or the care recipients. ${ }^{28}$. Sense of self-efficacy, feeling of accomplishment, a sense of meaning, satisfaction, well-being and improved quality of relationship; help to endure their role as a family caregivers. $^{33,34}$ The experience taking care of their elderly parents akin to the feeling of 'like caring for a regressing baby'; the cultural value of familism, or "a strong identification and attachment of individuals with their families, strong feelings of loyalty, reciprocity and solidarity among the family members," 35 , has been discussed in the literature. This may add the implications towards value of family care in our community setting. Strategies like psychoeducation intervention and cognitive behavioural therapy are effective in alleviating the caregiver's burden and depression, and improve subjective wellbeing, perceived satisfaction, ability/knowledge among caregivers, whilst also moderating patient symptoms. ${ }^{36}$ However, appropriate interventions to manage stress of care giving are still critical in view of logistic needs, time and cost.

Among the caregivers, some of them expressed feelings of being overwhelmed or trapped with the role as caregiver, similar with a study done by Chan (2010). ${ }^{37}$ They expressed the need for respite either by temporarily shifting the role of caregiver to other trusted family members or to other source of support, such as a day-care centre. However, such alternative assistance may not be easily or immediately available when needed. Hence, it became a source of major stress for the caregivers. It has been posited that involving family members is critical to the success of managing patients with dementia, and that older adults prefer to be treated within their family unit. ${ }^{38}$ Meyer et.al (2015) reported, that most of the time, caregivers need to take over the responsibility themselves due to lack of support even from close family members as the illness progresses. ${ }^{39}$

Overall, the practical aspects of provision of care to relatives of people with dementia are influenced by culture and religion and/or spirituality as a method of coping with burden of care demonstrated by most caregivers in this study, which resonate well with many other literatures which described about caregivers of patients with dementia. Involvement in religious or spiritual pursuits is a common way of coping. Spirituality acts as a motivational key in coping with stressful events. ${ }^{40,41}$ According to King and Koenig ${ }^{42}$, 'religion involves practices and beliefs about the sacred or divine whereas spirituality means something more closely related to emotional experience.' Religion has been described as part of spirituality. Spirituality can be mediated by the religion, the arts, the environment and the relationship with others and/or God. ${ }^{42}$ The spirituality can also be seen as a motivational factor or a way of coping in a stressful situation. ${ }^{43,44}$ In offering an explanation for the finding that non-organizational religiosity was associated with poorer mental health, Herrera et. al.(2009) observe that poorer mental health may be more prominent among caregivers who are unable to participate in public religious rituals (i.e., church attendance) as a result of increased care 
giving responsibilities and burden, which may lead them alternatively to seek relief through prayer and meditation. ${ }^{45}$

Filial piety is another important subtheme highlighted by the participants in this study. Allegiance to parents or spouse, or filial piety, is strongly valued in traditional Asian cultures. ${ }^{46,47}$ The sense of obligation may attribute greater risk for caregiver burden, stress and depression as evidence in study done among Asian American caregivers. ${ }^{48} \mathrm{~A}$ systematic review done among the Chinese American family caregivers demonstrated that their coping were influenced by cultural beliefs and emphasis of family harmony. ${ }^{49}$

In summary, all local ethnic groups have shown that culture, religion and/or spiritual influences have traditionally formed the framework of care for the participants as well as the inheritance of good moral values, even in these modern era. Spirituality seems fundamental to their care giving role. Until it is further clarified, religiosity and spirituality seemed interchangeable in this study; which describes a strong religious tradition among Malaysians, driven amongst all Muslim, Christian, Hindu and Buddhist participants. Hence, there is a great need for indepth exploration of the meaning of religiosity and spirituality in this community, which is not within the scope of this study.

\section{Implications for practice \& future research}

The findings support the multidimensional need of caregivers required to achieve potential benefit in their journey handling family members with dementia. Religion and spirituality have been identified as either a buffer from stress or a resource for coping in reducing burden and distress among Malaysian caregivers. Despite awareness of the need for multidisciplinary collaboration with caregivers of patients with dementia, division in responsibilities might have resulted in spirituality issues being handled by the religious authority or the community in isolation as a source for support. Hence, we propose that the bio-psycho-socialspiritual approach be considered as part of our service provision. An interventional approach such as development of one-stop multidisciplinary service provision for caregivers and dementia patients is worth considering for further research.

\section{Strength and Limitation}

The strength of this study is its ability to gain deeper understanding of the experiences of family caregivers caring for family members with moderate to severe dementia in the multicultural community of Malaysia. However, broad range of caregivers' age and types of dementia might contribute to different coping styles and different perception towards the illness. It was also a challenge to recruit the lower socio-economic group as our setting was in UKMMC; a semi-government hospital where patients need to pay, and it was a voluntary participation. Caregivers who neither spoke Malay or English not included in this study, are presumably from lower socioeconomic group and could have a stronger affiliation to the cultural influence. In addition, a greater level and depth of analysis would help to achieve a higher conceptual level of understanding and better transferability of findings.

\section{CONCLUSION}

Caring for a patient with dementia is an overwhelming and challenging experience for many family caregivers. The themes that we have outlined are an eye-opening experience for future research. Culturally tailored interventions for the Malaysian caregivers need to be implemented in order to contribute to their general well-being. This qualitative study elucidates the experiences of Malaysian caregivers where religious and spiritual dimensions facilitated the caregivers' journey as part of a salient coping strategy, to reduce the caregivers' burden. Development of collaborative partnerships between mental healthcare professionals and religious establishment / institutions might represent powerful resources in supporting the needs of caregivers' of family members with dementia.

\section{ACKNOWLEDGEMENT}

The authors would like to record their heartfelt thanks and appreciations to all participants and their family members who had participated in this study.

\section{Conflict of interest \\ None}

\section{REFERENCES}

1. Meyer L, Nguyen $\mathrm{KH}$, Dao TN, Vu P, Arean $\mathrm{P}$, Hinton L: The sociocultural context of caregiving experiences for Vietnamese dementia family caregivers. Asean American Pscyhological Association 2015; Vol.6, No.3, 263-272.

2. Chambers L, Hendriks A, Hall H, Raina R, McDowell I: Research on Alzheimer's caregiving in Canada:current status and future directions. Chronic Dis Can 2004;25(3/4):108-118.

3. Kim H, Chang M, Rose K, Kim S:Predictors of caregiver burden in caregivers of individuals with dementia. J Adv Nurs 2011; 68(4):846-855.

4. Bass DM, Judge KS, Snow AL, Wilson NL, Looman WJ, McCarthy C,Morgan R, Ablorth-Odjidja C, Kunik M: Negative caregiving effects among caregivers of veterans with dementia. Am J Geriatr Psychiatry 2012;20(3):239-247.

5. Huct CK: Concepts in caregiver research. J Nurs Scholarsh 2003;35(1):27-32.

6. Peacock S, Forbes D, Markle-Reid M, Hawranik $P$, et.al: The positive aspects of caregiving journey with dementia: using a strengths-based 
perspective to reveal opportunities. $\mathrm{J}$ of App Geron 2010;29:640-659.

7. Carbonneau H, Caron C,Desrosiers $\mathrm{J}$ :Development of a conceptual framework of positive aspects of caregiving dementia. Dementia 2012;9(3):327-353.

8. Pirani FM, Papadopoulos R, Foster J,\& Leavey G. I will accept whatever is meant for us. I wait for that-day and night: The search for healing at a Muslim shrine in Pakistan. Mental Health, Religion \& Culture, 2007;1-12.

9. Meeta M, Komilla T(2015). Religion and Coping with Caregiving Stress. Int.J. of

Multidisciplinary and Current research,2015; Vol.3(May/June2015)

10. Aranda MP, Knight BG. The influence of ethnicity and culture on the caregiver stress and coping process: A sociocultural review and analysis. The Gerontologist,1997;37,342354.

11. Knight BG, Sayegh P. Cultural values and caregiving: The updated sociocultural stress and coping model. The Journals of Gerontology: Series B: Psychological Sciences and Social Sciences, 2010;65B, 5-13.

12. Department of Statistics Malaysia. Characteristics of Key Household 2010 (update, 29.1.2014). http:// www.statistics.gov.my

13. Choo WY, Low WY, Karina R, Poi PJ, Ebenezer E, Prince MJ. Social support and burden among caregivers of patients with dementia in Malaysia. Asia Pac J Public Health. 2003;15 (1):23-29.

14. Rosdinom R, Norzarina MZ, Zanariah MS, Ruzanna ZZ. Socio-demographic Profiles of Caregivers and Their Association with Burden of Care in Dementia. MJP.2011.

15. Donaldson C, Tarrier N, Burns A.

Determinants of carer stresses in Alzheimer's Disease. Int J Geriatr Psychiatry. 1998;13:248 $-256$.

16. Itsugi N, Yasuaki A, Masahiro U, et al. Gender of demented patients and specific family relationship of caregiver to patients influence mental fatigue and burdens on relatives as caregivers. Int J Geriatr Psychiatry. 1999;14:618-624.

17. Gallichio L, Siddiqi N, Langenberg P, Baumgarten $M$. Gender differences in burden and depression among informal caregivers of demented elders in the community. Int $\mathrm{J}$ Geriatr Psychiatry 2002;17(2):154-163.

18. Wallis J, Margareta G, Bengt W. Daughters and sons as caregivers for their demented and non-demented elderly parents. A part of a population-based study carried out in Sweden. Scand J Soc Med. 1997;25(40):289295.

19. Robert F. Coen, Ciaran O'Boyle, Davis Coakley. Behaviour disturbance and other predictors of carer burden in Alzheimer's Disease. Int J Geriatr Psychiatry. 1997;12:331
$-336$.

20. Almberg Britt, Margareta Grafstrom,Bengst Winblad. Caring for a demented elderly personburden and burnout among caregiving relatives. J Adv Nurs.1997;25(1):109-116.

21. Karin J. Faison, Sandra H. Faria, Deborah Frank. Caregivers of Chronically Ill Elderly: Perceived Burden. J Community Health Nurs.1999; Volume 16 , Issue 4,243-253.

22. Merriam SB. Qualitative research in Practice: examples for discussion and analysis. San Francisco; Jossey-Bass, 2002.

23. Patton MQ. Qualitative Research and Evaluation Methods. $3^{\text {rd }}$ edition, Sage Publications. Thousand Oaks, CA.2002.

24. Guest G, Bunce A, Johnson L. How many interviews are enough? An experiment with saturation and variability. Filed Methods, 2006;18(1), 59-82.

25. Braun, V., \& Clarke, V. Using thematic analysis in psychological. Qualitative research in psychology, 2006;3, 77-101.

26. Yeo G, Uyen Tran JN, Hikoyeda N, Hinton L.Conceptions of dementia among Vietnamese American caregivers. Journal of Gerontological Social Work, 2002;36,131-152. http:// dx.doi.org/10.1300/J083v36n01_08

27. Rosdinom R., Zarina M.Z.N, Marhani M., Suzaily W. Behavioural and psychological symptoms of dementia, cognitive impairment and caregiver burden in patients with dementia. Preventive Medicine;Vol.57, Supp, 2013;S67-S69. http:// dx.doi.org/10.1016/j.ypmed.2012.12.025

28. WC Chan, C Ng, CCM Mok, SL Pang, HFK Chiu., et al. A Lived Experience of Caregivers of Persons with Dementia in Hong Kong: a Qualitative Study. East Asian Arch Psychiatry 2010; Vol 20, No.4.

29. Aneshensel CS, Pearlin LI, Mullan JT, Zarit SH, Whitlacth CJ. Profiles in caregiving: The unexpected carer. New York, NY: Academic Press.1995

30. Turner S, Christie A, Haworth E. South Asian and white older people and dementia: a qualitative study of knowledge and attitudes. Diversity in Health and Social Care 2005;2:197-209.

31. Liu D, Hinton L, Tran C, Hinton D, Barker JC. Reexamining the relationships among dementia, stigma, and aging in immigrant Chinese and Vietnamese family caregivers. Journal of Crosscultural Gerontology, 2008;23, 283-299. http:// dx.doi.org/10.1007/s10823-00809075-5

32. Endrawes G, O’Brien L, Wilkes L. Egyptian families caring for a relative with mental illness: A hermeneutic study. International Journal of Mental Health Nursing,2007;16(6), 431-440. Doi:10.1111/j.1447-0349.2007.00498.x

33. Peacock S, Forbes D, Markle-Reid M, Hawranik P, et al.: The positive aspects of caregiving journey with dementia: using a strength-based perspective to reveal opportunities. J of App Geron 2010; 29:640-659.

34. Carbonneau H, Caron C, Desrosiers J: Development of conceptual framework of 
positive aspects of caregiving in dementia. Dementia 2012;9(3):327-353.

35. Sabogal F, Marin G, Otero-Sabogal R, Marin BVO, Perez-Stable EJ. Hispanic familism and acculturation: What changes and what doesn't? Hispanic Journal of Behavioural Sciences, 1987;9,397-412.

36. Bullock R. The needs of caregivers in the longterm treatment of Alzheimer disease. Alzheimer Dis Assoc Discord 2004;18 Suppl 1: S17-23

37. Chan SWC. Family caregiving in dementia. Dementia and Geriatric Cognitive Disorders, 2010;30, 469-478. http: / / dx.doi.org/10.1159/000322086

38. Gallgher-Thompson D, Rabinowitz Y, Tang, PC, Tse C, Kwo E, Hsu S, Thompson LW. Recruiting Chinese Americans for dementia caregiver intervention research: Suggestions for success. The American Journal of Geriatric Psychiatry, 2006;14, 676-683. http:// dx.doi.org/10.1097/01.JGP.0000221234.65585. 19

39. Meyer OL, Nguyen KH, Dao TN, Vu P, Arean P, Hinton L. The sociocultural context of caregiving experiences for Vietnamese dementia family caregivers. Asian American Journal of Psychology,2015; Vol.6, No.3,263272.

40. Hill PC, Pargament KI. Advances in the conceptualization and measurement of religion and spirituality: Implications for physical and mental health research. American Psychologist, 2003;58(1), 64-74.

41. Krause N. Gratitude toward God, stress, and health in late life. Research on Aging, 2006;28 (2), 163-83.

42. King MB, Koenig HG. Conceptualizing spirituality for medical research and health service provision. BMC Healh Service Research, 2009;13(9),116. Doi:10.1186/1472-6963-9-116.

43. MacKinlay E. Spiritual Care: Recognising Spiritual Needs of Older Adults, Journal of Religion, Spirituality and Aging, 2006;18(2),5971.

44. Pargament KL, Brant CR. Religion and coping. In H.G.Koenig (ed), Handbook of Religion and Mental Health, San Diego, CA:Academic Press, 1998;111-28.

45. Herrera AP, Lee JW, Nanyonjo RD, Laufman LE, Torres-Vigil I. Religious coping and caregiver well-being in Mexican-American families. Aging and Mental Health,2009;13(1),84-91.

46. Uba L. Asian Americans: Personality patterns, identity, and mental health. New York,NY: Guilford Press.1994

47. Zan N,Yeh M. The use of culturally-based variables in assessment: Studies on loss of face. In K.S. Kurasaki, S. Okazaki, \& S.Sue (Eds.), Asian American mental health: Assessment theories and methods New York, NY:Kluwer Academic/Plenum Press Publishers.

2002;pp.123-138. http:// dx.doi.org/10.1007/978-1-4615-0735-2_9

48. Wang DS. Caregiving for dementia in Asian communities: Implications for practise. Journal of Ethnic \& Cultural Diversity in Social Work: Innovation in Theory, Research \& Practise, 2012;21, 249-273.

49. Sun F, Ong R, Burnette D. The influence of ethnicity and culture on dementia caregiving: A review of empirical studies on Chinese Americans. American Journal of Alzheimer's Disease \& Others Dementias, 2012, 27(1), 1322. 